\title{
AUTORIA NA REDAÇÃO CIENTÍFICA ${ }^{1}$
}

\section{AUTORÍA EN LA REDACCIÓN CIENTÍFICA}

Marcelo Krokoscz - krokoscz@uol.com.br Doutor em Educação pela Universidade de São Paulo (USP). Professor de Metodologia da Pesquisa da Fundação Escola de Comércio Álvares Penteado (FECAP).

\section{RESUMO}

Introdução: O texto apresenta uma análise ensaística sobre as possíveis modalidades de autoria a partir de sua definição e reflete sobre a complexidade e necessidade de busca de critérios de atribuição de autoria.

Objetivos: $O$ trabalho visa discutir alguns aspectos importantes e necessários relacionados à concepção de autoria científica. Consequentemente, esta tarefa requer: identificar e analisar a definição de autoria; reconhecer e debater alguns aspectos e critérios compartilhados pela academia em relação à autoria.

Metodologia: A reflexão é contextualizada bibliograficamente com algumas ideias de outros autores sobre o assunto, ao mesmo tempo em que procura contribuir com algumas pistas e propostas de discussão relacionadas ao tema as quais visam fomentar o debate e aprofundar a compreensão sobre a autoria científica.

Resultados: O trabalho sistematiza o conceito de autoria e apresenta a ideia de "catavento autoral". Destaca a complexidade dos fatores envolvidos no estabelecimento da autoria científica, seja do ponto de vista da inexistência de consensos sobre os critérios que definem a autoria de um trabalho, bem como em relação às demandas e pressões pelo produtivismo das publicações. A partir disto, apresenta dois esquemas/modelos de autoria.

Conclusões: a atribuição e reconhecimento da autoria científica ainda é uma condição que depende muito mais de princípios éticos dos próprios autores do que das regras e das convenções instituídas.

Palavras-chave: Autoria. Redação científica. Plágio. Ética.

\footnotetext{
${ }^{1}$ Transparência autoral: Este trabalho contém partes na íntegra da tese de doutorado do mesmo autor intitulada "OUTRAS PALAVRAS: Análise dos conceitos de autoria e plágio na produção textual científica no contexto pós-moderno" que foi apresentada à Faculdade de Educação da Universidade de São Paulo em 2014 e publicada em 2015 pela Editora Atlas com o título: "Outras palavras sobre autoria e plágio".
} 


\section{INTRODUÇÃO}

Uma das etapas culminantes do processo de produção científica é a apresentação dos resultados obtidos o que geralmente é feito por meio de textos que são elaborados seguindo a estrutura acadêmica: introdução, fundamentação, descrição de métodos, resultados, discussão, conclusões e fontes de pesquisa. Este trabalho é veiculado para a comunidade científica especificamente e a sociedade em geral por meio de revistas científicas caracterizadas pelo estabelecimento de diretrizes para a publicação que além do formato acadêmico do trabalho a ser publicado, geralmente requerem que o mesmo trate de temática original, apresente resultados confiáveis, tenha contribuições importantes para a ciência e a humanidade e que seja assinado por pesquisadores íntegros, pessoas capazes tecnicamente e honestas eticamente.

Portanto, do ponto de vista da comunicação científica, por um lado se tem uma pesquisa a ser apresentada, que se constitui numa obra descrita passo a passo em um texto e de outro lado, alguém que é o responsável pela mesma, o autor que pode ser uma pessoa, um grupo ou uma instituição. Entretanto, esta relação entre obra e autor no processo de comunicação científica é permeada por diversos aspectos e fatores que a caracterizam de forma complexa e problemática, os quais se encontram enredados em um conjunto de indagações: O que importa mais, a obra ou o autor? O que caracteriza um autor? Quais são os critérios para atribuição de autoria científica? As obras (trabalhos) mais citados são as mais importantes?

Embora este trabalho de caráter mais ensaístico do que científico, não tenha o escopo de responder especificamente a cada uma destas questões, o principal objetivo deste texto é discutir alguns aspectos importantes e necessários relacionadas à concepção de autoria científica. Consequentemente, esta tarefa requer que sejam cumpridas as seguintes etapas: identificar e analisar a definição de autoria; reconhecer e debater alguns aspectos e critérios compartilhados pela academia em relação à autoria.

A temática deste trabalho apresenta-se como relevante, porque antecede a problemática do plágio acadêmico, um desafio que vem preocupando todas as esferas da produção científica, desde a graduação. Portanto, entende-se que embora o plágio seja uma fraude autoral que precisa ser enfrentado e combatido, 
faz-se necessário reconhecer que concomitantemente é fundamental que a academia aprofunde a sua reflexão sobre o que se entende sobre a autoria, este status almejado ou ignorado no trabalho de escrita científica. Além de relevante, este trabalho propõe-se a contribuir para o esclarecimento e compreensão da conceituação de autoria científica. Embora não apresente de forma conclusiva teorias fundamentadas, o trabalho sistematiza ideias em discussão e traz algumas pistas e propostas de reflexão que podem fomentar um debate que faz parte do processo de produção científica, mas que precisa ser aprofundado.

\section{MODALIDADES DE AUTORIA}

De acordo com o dicionário Caldas Aulete o verbete "autor" está relacionado, entre outras, às seguintes acepções: "1. Criador de obra literária, artística ou científica; 2. Pessoa responsável por uma invenção ou descoberta; 3. Pessoa que faz, realiza, comete, um ato ou fato; a primeira pessoa a divulgar algo; [...] 7. Pessoa responsável pela fundação ou instituição de algo." (AULETE DIGITAL, 2015).

As palavras-chave que podem ser destacadas destas conotações são os termos: criação, invenção, descoberta, fundação. Todas estas palavras estão correlacionadas com a ideia central de ação, ou seja, a acepção que, de acordo com o dicionário, se refere à "pessoa que faz, realiza, comete, um ato ou fato; a primeira pessoa a divulgar algo". Desta maneira, toda pessoa é por natureza autor, de alguma maneira, de alguma coisa: é autor o sujeito que age de forma jubilosa como um atleta que bate um recorde mundial no atletismo, ou o sujeito que comete uma ação condenável como um criminoso que assassina pessoas deliberadamente durante uma sessão de cinema. Mas também é autor o sujeito que inventa um meio de transporte, um acessório doméstico ou um recurso de comunicação; a pessoa que descobre a cura de uma doença, que identifica uma nova espécie na natureza ou explica o surgimento do universo; alguém que funda uma rede social, organiza uma competição esportiva mundial ou inicia uma ordem religiosa; é autor quem cria uma obra; compõe uma sinfonia ou escreve um livro. 
Quadro 1 - Exemplos de produtos de autoria em diferentes modalidades

\begin{tabular}{|c|c|c|c|c|}
\hline \multicolumn{5}{|c|}{ AUTORIA $\Leftrightarrow$ AÇÃO HUMANA } \\
\hline AÇÃO & Inventar & Descobrir & Fundar & Criar \\
\hline Jogar & Avião & Penicilina & Facebook & Monalisa \\
\hline Matar & Escrita & Evolução & Olimpíadas & Bachianas \\
\hline Discursar & Internet & Átomo & Jesuítas & Dom Casmurro \\
\hline
\end{tabular}

Fonte: elaborado pelo autor.

Portanto, pode-se argumentar que cada pessoa é por natureza autor na vida. A autoria é uma característica da cultura humana, pois se trata de tudo aquilo que o ser humano produz no dia-a-dia, no mundo artístico, técnico, científico ou social, de forma positiva ou negativa. E em cada uma destas áreas autorais é possível identificar com mais ênfase uma das palavras-chave apresentadas anteriormente. Contudo, ainda que na área técnica a autoria seja caracterizada essencialmente pela invenção, não se pode deixar de pressupor que muitos inventos decorrem de uma boa dose de criatividade, da mesma forma que uma descoberta científica resulta no invento de um equipamento e a fundação de uma rede social requer conhecimentos científicos e técnicos de informática. Então, apesar da autoria poder ser caracterizada com termos específicos mais ou menos identificados em cada área da ação humana, é preciso considerar uma relação/influência das características nas diferentes áreas num processo que originalmente chamamos de catavento autoral. 
Figura 1 - Cata-vento autoral

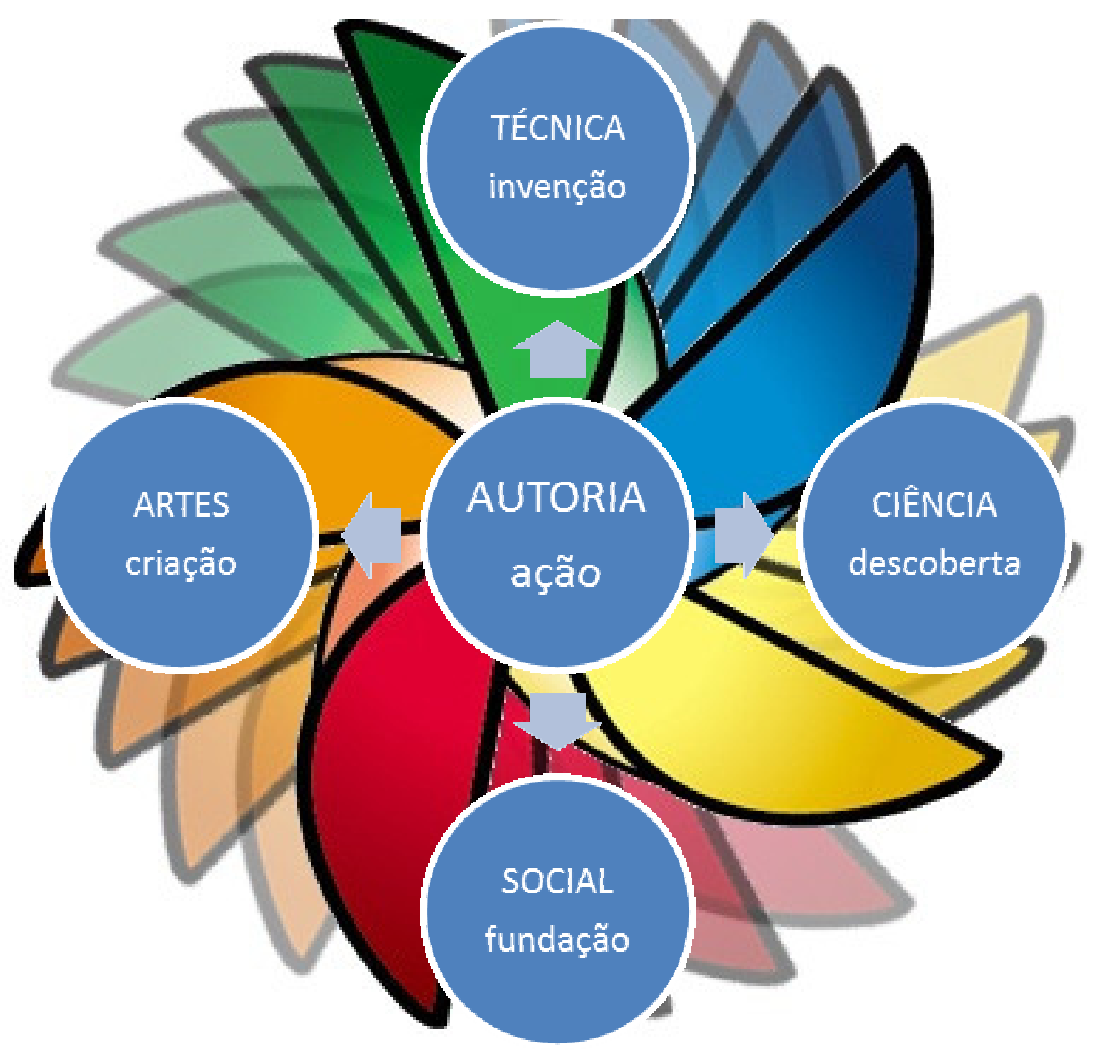

Fonte: elaborado pelo autor.

Considerando-se isto, pode-se supor então que apesar da autoria científica ser um processo essencialmente caracterizado pela descoberta, também é influenciado pela criatividade, inventividade e novidade, uma característica, diga-se de passagem, comum na biografia dos cientistas.

\section{CRITÉRIOS DE AUTORIA}

Encontram-se na discussão sobre o processo de autoria (descoberta) científica, opiniões de que tal atividade corresponde basicamente a dois critérios: contribuição para o progresso da ciência e reconhecimento pessoal (reputação, prestígio, promoção) (MONTEIRO et al., 2004; PETROIANU, 2002). Embora também se considere que entre os aspectos gerais envolvidos na autoria científica seja preciso elencar a importância/influência de fatores como a formação do indivíduo (que tem a ver com a subjetividade do pesquisador), bem como as regras científicas, os códigos e a legislação da ciência, a medição da produtividade 
científica (aspectos relacionados à operacionalidade da autoria científica) (WITTER, 2010).

Um recorte específico da atividade científica na qual se manifesta a autoria refere-se ao trabalho de comunicação dos resultados que em geral é feito de forma escrita por meio da redação bibliográfica. Os pesquisadores que assinam tais textos são reconhecidos como autores. Neste sentido, associações que congregam pesquisadores apresentam conceituações sobre a autoria científica tal como "a pessoa ou pessoas responsáveis primárias pelos dados e conceitos e pelas análises e interpretações de um trabalho publicado ou a ser publicado. Não é apenas quem escreveu o texto, mas inclui todos os que deram contribuição substancial ao estudo." (AMERICAN PSYCHOLOGICAL ASSOCIATION, 2007 apud WITTER, 2010, p. 131). Para o International Committee of Medical Journals Editors (ICMJE) o crédito da autoria científica corresponde ao preenchimento de três condições: "1. Contribuição substancial na concepção e planejamento, ou aquisição de dados, ou análise e interpretação de dados; 2. Redação e elaboração do artigo ou revisão intelectual crítica deste; 3. Aprovação da versão final a ser publicada" (MONTEIRO et al., 2004).

Não obstante, é pertinente a observação feita no estudo realizado por Monteiro et al. (2004) de que os critérios de autoria apresentados pelo ICMJE são adotados pela metade dos periódicos de uma amostra de 40 revistas da área da saúde indexadas no Scielo. Além disso, o estudo observou que

[...] sete $(17,5 \%)$ revistas adotam política de restrição do número de autores permitidos por artigo; sete (17,5\%) explicitam os critérios que definem autoria; quatro (10\%) adotam a prática de exigir aprovação das pessoas que terão seus nomes listados na sessão agradecimentos; cinco (12,5\%) solicitam declaração de conflito de interesse. (MONTEIRO et al., 2004).

Portanto, constata-se que a atribuição da autoria aos responsáveis por trabalhos científicos é assunto complexo que envolve aspectos subjetivos, objetivos e operacionais. Apesar de haver algumas reflexões sobre a temática, ainda inexiste consensos generalizados sobre os critérios que definem a autoria, e mesmo nas áreas em que isto já possui diretrizes, a adoção de tais critérios na prática editorial ainda é incipiente. Por isto, Monteiro et al. (2004) concluem que é necessário um esforço coletivo de autores, editores e sociedades em adotar critérios de autoria 
dada a importância disto do ponto de vista dos pressupostos éticos que devem pautar a produção e a divulgação científica.

Em relação a esta necessidade de estabelecimento de critérios de autoria científica, é interessante observar a proposta de Petroianu (2002) que corresponde à criação de uma tabela de pontuação variável para cada modalidade de participação de um sujeito no processo de pesquisa. Pode-se considerar autor científico de um trabalho todos os sujeitos envolvidos num trabalho que alcancem 7 pontos na Tabela 1.

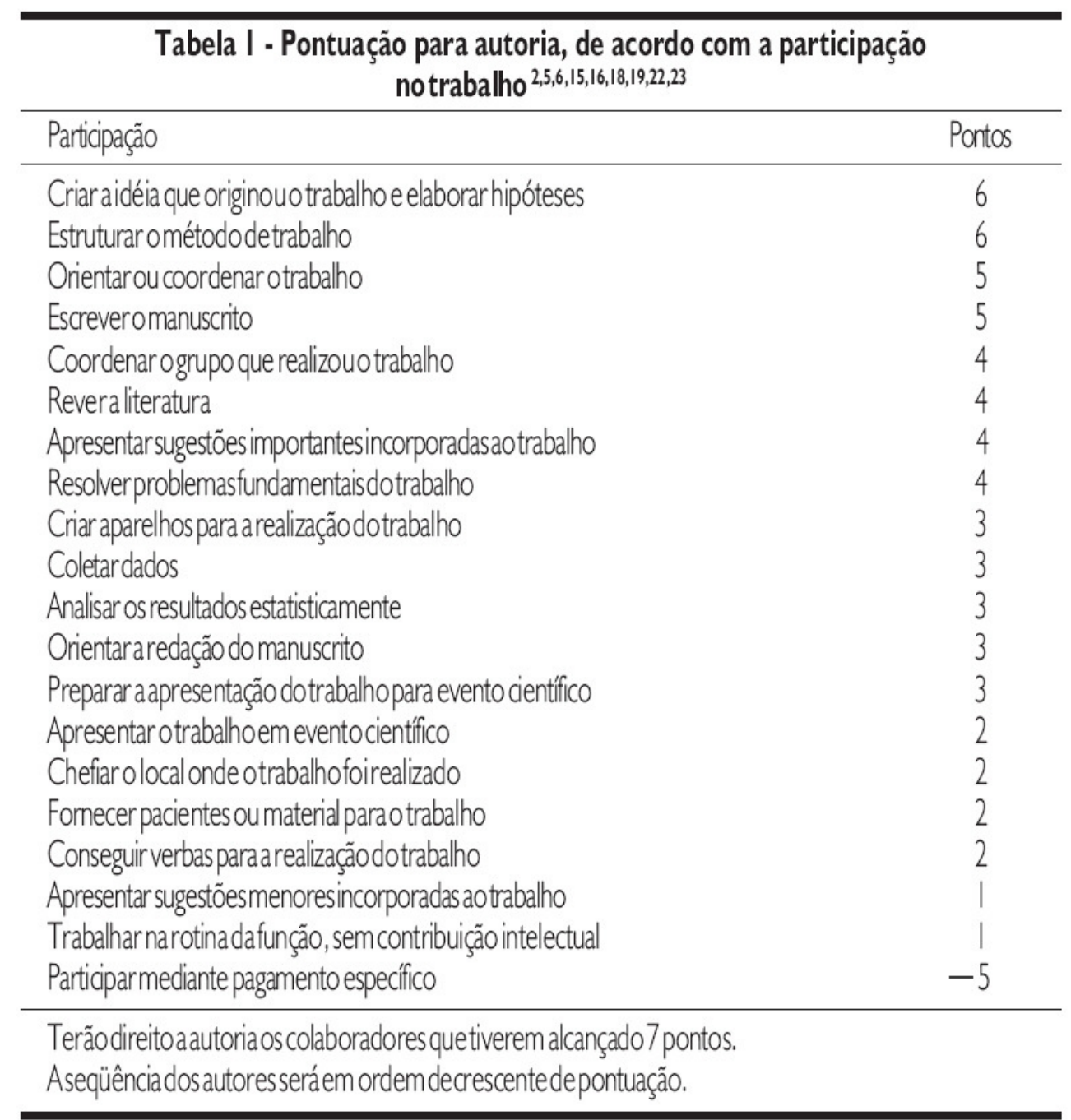

Fonte: Petroianu (2002).

Esta proposta é interessante, contudo ainda requer fundamentação, pois embora as modalidades contempladas pelo autor correspondam às diversas possibilidades de participação de um sujeito no processo de pesquisa, problematizase a atribuição da pontuação para cada modalidade bem como a justificativa de que 
a autoria fica instituída para o sujeito que soma 7 pontos. Petroianu (2002, p.65) não apresenta uma justificativa técnica para esta escala e assume isto concluindo que a proposta apresentada reflete "[...] pontos de vista de seu autor com base na literatura, avaliação de centros de pesquisa e vivência científica pessoal" cabendo ao leitor seguir ou não o modelo proposto.

Esta fragilidade observada na proposta de Petroianu destaca-se se comparada ao trabalho de outra autora. A escala proposta por Petroianu é adotada por Witter (2010), porém a pontuação atribuída passa a ser outra. A autora acena uma justificativa de mudança na pontuação recorrendo também à própria experiência e reconhece a necessidade de validação científica de tal escala.

Portanto, diante da importância e necessidade do estabelecimento de critérios de definição da autoria em textos científicos, iniciativas de apresentação de propostas como as apresentadas acima são louváveis e até podem servir como referência, mas ainda requerem aprimoramento e validação para que passem a ser consensualmente aceitas.

\section{A COMPLEXIDADE DA AUTORIA CIENTÍFICA}

Além da dificuldade relacionada ao estabelecimento dos critérios que determinam a autoria científica é preciso reconhecer a influência de outros fatores que amplificam a complexidade relacionada a este problema, caso da pressão sofrida pelos pesquisadores e cientistas por parte da academia no que diz respeito à necessidade de publicação científica que há muito tempo vem sendo debatida (ANGELL, 1986).

Em relação a este assunto, Petroianu (2002) destaca o pressuposto compartilhado por muitos pesquisadores de que em geral são julgados pela quantidade de trabalhos publicados, qualidade e tipo de periódico de veiculação. Submetida a isto, a autoria científica deixa de ser espontânea e criativa e passa a ser encarada como mais um produto de circulação. $O$ trabalho científico deixa de ser um fim e passa a ser um meio de reconhecimento e credibilidade.

Sob o jugo da necessidade de produzir e publicar, ao começar a redigir um trabalho científico, o pesquisador já seleciona em qual periódico deseja publicar tal trabalho, observando a classificação do mesmo no ranking de "qualidade científica" (Fator de Impacto) um índice que corresponde à média do número das citações que 
os trabalhos publicados em um determinado periódico recebem em outros artigos. Objetivamente, os periódicos com maior fator de impacto são os que publicam os melhores artigos científicos e mais citados, ou seja, que possuem mais visibilidade. Então, a expectativa de um autor de ser visto e citado por outros aumenta de acordo com o fator de impacto do periódico no qual ele publica.

Este processo acaba tendo discrepâncias porque os periódicos com maior fator de impacto acabam sendo inflacionados com um número elevado de artigos submetidos e com isto possuem uma grande oferta que permite selecionar os melhores entre muitos ao mesmo tempo em que periódicos com baixo fator de impacto recebem poucas submissões, não conseguem ter trabalhos de alta qualidade e assim dificilmente conseguem melhorar de fator de impacto porque seus trabalhos publicados são pouco citados, ou ainda que publiquem trabalhos de alta qualidade, acabam não sendo vistos porque as bases de dados privilegiam a indexação de periódicos com alto fator de impacto. Trabalhos publicados em periódicos fora das bases de dados têm maior dificuldade para serem recuperados no processo de levantamento de dados. Eis o dilema de muitos periódicos comentado por Packer (2011), diretor do Scielo: "Como ter fator de impacto se não sou indexado? Como ser indexado se não tenho fator de impacto?"

Considerando-se a complexidade envolvida neste contexto, consequentemente, a autoria científica torna-se refém de uma série de dissimulações e fraudes. De acordo com Monteiro et al. (2004) parte dos trabalhos científicos passam a ter sua autoria e/ou coautoria caracterizadas como "convidada" (nomes de amigos que são elencados como autores sem que tenham tido nenhuma participação no trabalho); autoria e/ou coutoria "pressionada" (pesquisadores cujo nome são relacionados a estudos feitos por outros apenas para aferir autoridade ao trabalho); autoria e/ou coautoria "fantasma" (trabalhos que são apresentados como sendo próprios, porém foram produzidos por terceiros). Além disto, Petroianu (2002), fala sobre a existência da "autoria honorária" (autoria atribuída a alguém com o intuito de homenagem, privilégio ou retribuição de gentileza). Domingues (2012) elenca ainda uma série de outras fraudes que descaracterizam ou comprometem a autoria científica tais como: falsificação e/ou fabricação de dados e resultados; plágio de trabalhos; imposturas éticas no processo científico; retalhamento, fracionamento e ou requentamento de dados e resultados. Em suma, trata-se de um conjunto de modalidades de fraudes autorais que decorrem de um enviesamento do 
escopo da produção científica na qual a pessoa passa a ser mais importante do que a obra.

Portanto, notam-se simultaneamente dois modelos de produção científica que implicam numa ambiguidade na interpretação do sentido da autoria. O modelo qualitativo pressupõe a importância da descoberta, ou seja, da objetividade da obra científica e sua importância para o aprimoramento humano; no modelo quantitativo prevalece a importância do sujeito, ou seja, da subjetividade do pesquisador e sua credibilidade diante dos pares e da academia. Enquanto este modelo é caracterizado pela "contabilidade" de trabalhos publicados, naquele destaca-se a "representatividade" da obra apresentada para o avanço do conhecimento.

Quadro 2 - Modelos de autoria científica

\begin{tabular}{|c|c|}
\hline \multicolumn{2}{|c|}{ MODELOS DE AUTORIA } \\
\hline $\begin{array}{c}\text { Modelo Qualitativo } \\
\text { Obra }\end{array}$ & $\begin{array}{c}\text { Modelo Quantitativo } \\
\text { Sujeito }\end{array}$ \\
\hline $\begin{array}{c}\text { Sumanidade } \\
\text { Sujeito }\end{array}$
\end{tabular}

Fonte: elaborado pelo autor

Contudo, seria equivocado interpretar este esquema pressupondo que um modelo é melhor ou pior que o outro. Por um lado, destaca-se a importância do modelo qualitativo no qual a obra é o ponto de partida e se destaca no processo de produção/publicação científica devida a sua importância teórica/técnica para o desenvolvimento da humanidade é o que se constata, por exemplo, com a invenção do avião: um dos meios de transporte mais revolucionários e importantes na história da humanidade por implicar na ressignificação das noções de tempo e espaço. Uma obra cuja importância comercial, cultural e tecnológica para a humanidade é inquestionável, mas cuja autoria ainda hoje é motivo de polêmica.

Por outro lado, não se pode prescindir da necessidade do modelo quantitativo no qual o sujeito prevalece sobre a obra, justamente pelo papel de aferição de credibilidade e fiabilidade a um trabalho que é apresentado como novidade científica. Neste caso, pode-se ilustrar com o caso da teoria cosmológica de Peter 
Higgs sobre a origem do universo. A chamada "partícula de Deus" ou bóson de Higgs foi o ponto de partida para a explicação teórica formulada pelo cientista para o início do mundo embora, até recentemente, não tivesse constatação empírica. Neste caso, a credibilidade científica do pesquisador obtida pela integridade de sua história, capacidade intelectual e reconhecimento da comunidade tornam-se atestados pessoais para a sua obra. Em outras palavras, a importância de um trabalho científico também é decorrência da pessoa (autor) que o apresenta, ainda que isto não seja uma regra. Basta lembrar que quando Einstein apresentou a Teoria do Efeito Fotoelétrico em 1905 ainda era um desconhecido funcionário de registro de patentes e sua teoria passou praticamente ignorada até ser notadamente reconhecida em 1921 quando Ihe foi concedido o Prêmio Nobel de Física.

Portanto, seria mais adequado pensar na utilização do modelo qualitativo $E$ quantitativo, do que debater a prevalência de um OU outro. Entretanto, inicialmente é preciso lidar com as discrepâncias decorrentes da utilização dos atuais índices de mensuração da autoria/produtividade científica sejam eles indicadores-produto ou indicadores de impacto.

Indicadores bibliométricos são indicadores-produto (ou ainda indicadores de eficácia) quando se referem a resultados mais imediatos das políticas com a produção de artigos em C\&T ou número de patentes. São indicadores de impacto (ou indicadores de efetividade social) quando se referem a desdobramentos mais a médio prazo ou a efeitos mais abrangentes e perenes do fomento às atividades de C\&T, como o Fator de Impacto de Publicações e outras medidas - não bibliométricas - como a Taxa de Inovação Tecnológica, o Balanço de Pagamentos Tecnológico, o grau de apropriação de tecnologia nacional na produção de medicamentos, na Saúde Pública, no desenvolvimentos de novos materiais para construção de moradias etc. (MUGNAINI; JANNUZZI; QUONIAM, 2004, p. 124, grifos do autor).

Entre tais indicadores, destacam-se o Fator de Impacto, proposto por Eugene Garfield em 2002 e o Índice h, medida apresentada por Jorge E. Hirsch em 2005. Com o mesmo escopo do Fator de Impacto, o índice h apresenta-se como um estimador da produtividade científica de pessoas, grupos ou países de acordo com a quantidade de citações recebidas que corresponde ao número de artigos com citações maiores ou iguais a ele. Então um autor com índice $h=3$ corresponde ao fato de ter três artigos publicados os quais receberam pelo menos três citações. $O$ problema é que um autor pode ter índice $h=1$ com centenas de citação enquanto 
outro pode ter índice $\mathrm{h}=2 \mathrm{com}$ apenas duas citações. Ou seja, o índice pode não corresponder à importância do trabalho ou do autor.

Em síntese, parece ficar evidenciado que a atribuição e o reconhecimento de autoria em trabalhos científicos são questões problemáticas e complexas devido à especificidade dos grupos e áreas de pesquisa, à variedade de critérios envolvidos, aos fatores de influência sobre os indivíduos, à fragilidade dos indicadores disponíveis. Não obstante, a necessidade do estabelecimento de um consenso mínimo sobre os aspectos determinantes da autoria científica é uma demanda perene que corresponde diretamente à manutenção dos padrões éticos requeridos pela ciência bem como a conservação da credibilidade dos resultados que são apresentados à comunidade científica e à sociedade em geral.

\section{AUTORIA, ÉTICA E CONTRIBUIÇÃO CIENTÍFICA}

Pensando nisto, torna-se desejável a criação do que poderia ser chamado de um Índice de Contribuição Científica, ou seja, uma escala de mensuração da contribuição efetiva que determinados estudos apresentados trazem para o desenvolvimento humano de acordo com certos aspectos fundamentais relacionados a isto. Tratar-se-ia da elaboração de uma escala semelhante ao Índice de Desenvolvimento Humano (IDH), elaborado pelos economistas Mahbub ul Haq e Amartya Sen para medir o grau de desenvolvimento das sociedades de acordo com as variações ocorridas nas áreas específicas de escolaridade, rentabilidade e longevidade. Em termos de avanço científico, as áreas essenciais de avaliação poderiam ser estabelecidas como inovação, aplicação e contribuição para a melhoria da humanidade, algo semelhante ao que é feito para a atribuição do Prêmio Nobel.

Deixando à parte o devaneio, objetivamente o que se pode concluir em relação à autoria científica é que embora a temática requeira aprofundamento, esclarecimento e aprimoramentos, um pressuposto que se impõe de forma indiscutível é que se trata de algo estreitamente relacionado à ética e, portanto, mais do que regras, requer principalmente princípios inegociáveis que dizem respeito ao indivíduo, aos grupos e à sociedade.

Witter (2010) citando Trzesniak e Koller (2009) observa que produzir ciência de forma ética, por um lado implica na observância do detalhamento e veracidade do que é apresentado. Mas a autora é veemente em afirmar que "não se deve aceitar 
aparecer como autor em trabalho para o qual não tenha realmente contribuído de forma substantiva." (WITTER, 2010, p.137). Ou seja, na prática, realmente o que faz a maior diferença, é a consciência e a decisão pessoal do pesquisador que sabe melhor do que ninguém até aonde vai a sua importância e contribuição em um estudo.

A honestidade pessoal do pesquisador sempre será o melhor critério de definição de autoria, o problema é que em geral parece que a satisfação dos próprios interesses acaba recompensando muito mais do que o reconhecimento público da integridade. Enquanto TER continuar sendo mais importante do que SER, dificilmente será resolvido o problema da autoria de forma específica como de todos os outros em geral relacionados à humanidade. Consequentemente banaliza-se a ocorrência do plágio em trabalhos acadêmicos, uma degeneração da autoria que consiste em PARECER cuja implicação prática é a erosão do conhecimento. Mas isto é uma reflexão para uma outra oportunidade.

\section{REFERÊNCIAS}

ANGELL, M. Publish ou perish: a proposal. Annals of Internal Medicine, v. 104, p. 261-262, 1986.

AULETE DIGITAL. Autor. 2015. Disponível em: <http://www.aulete.com.br/autor>. Acesso em: 27 abr. 2015.

DOMINGUES, I. A questão do plágio e da fraude nas humanidades. Ciência Hoje, v. 49 , p. 36-41, 2012.

MONTEIRO, R.; JATENE, F. B.; GOLDENBERG, S.; POBLACION, D. A.; PELLIZZON, R. DE F. Critérios de autoria dos trabalhos científicos: um assunto polêmico e delicado. Brazilian Cardiovascular Surgery, v. 19, n. 4, 2004.

MUGNAINI, R.; JANNUZZI, P. M.; QUONIAM, L. Indicadores bibliométricos da produção científica brasileira: uma análise a partir da base Pascal. Ciência da Informação, Brasília, v. 33, n. 2, p. 123-131, maio/ago. 2004

PACKER, Abel. Os periódicos brasileiros na comunicação científica nacional. In: Curso de Editoração Científica da ABEC, 19., 2011. Campinas. Apresentação oral... Campinas: Instituto de Agronomia de Campinas, 2011.

PETROIANU, A. Autoria de um trabalho científico. Revista da Associação Médica Brasileira, v. 48, n. 1, p. 60-65, mar 2002. 
WITTER, G. P. Ética e autoria na produção textual científica. Informação \&

Informação, v. 15, n. Especial, p. 130 - 143, 2010.

\title{
Title
}

Authorship in scientific writing

\begin{abstract}
Introduction: This text presents an analysis of possible ways of authorship from its definition and reflects on the complexity and need to search for authorship criteria.

Objectives: The article discusses some important and necessary aspects related to scientific authorship. Consequently, this task requires identify and analyze the definition of authorship; recognize and discuss some aspects and criteria shared by the academy in relation to authorship

Methodology: Reflection is contextualized bibliographically with some other authors of ideas on the subject at the same time it seeks to contribute some discussion slopes and proposals related to the theme which aim to stimulate debate and deepen understanding about scientific authorship.

Results: This article systematizes the concept of authorship and presents the idea of "authorship weathervane". Highlights the complexity of factors involved in the establishment of scientific authorship, from the point of view of the lack of consensus on the criteria that define the authorship of a work as well as in relation to the demands and pressures productivism publications. From this it presents two schemes / authoring templates.

Conclusions: The atribution and recognition of scientific authorship is still a condition that depends much more on ethical principles of the authors than the rules and conventions imposed.
\end{abstract}

Key words: Authorship. Scientific writing. Plagiarism. Ethics.

\section{Título}

Autoría en la redacción científica

\section{Resumen}

Introducción: El texto presenta un ensayo de las posibles formas de autoria, de su definición y reflexiona sobre la complejidad y la necesidad de buscar criterios de autoría.

Objetivos: El artículo analiza algunos importantes y necessários aspectos en relación con la autoría científica. En consecuencia, esta tarea requiere la identificación y el análisis de la definición de autoría; reconocer y discutir algunos aspectos y criterios compartidos por la academia con respecto a la autoría.

Metodología: A reflexión se contextualiza bibliográficamente con las ideas sobre el tema de otros autores, al mismo tiempo que se procura aportar algunos elementos de discusión y propuestas relacionadas con el tema que tienen como objetivo estimular el debate y profundizar el conocimiento sobre la autoría científica. 
Resultados: En este artículo se sistematiza el concepto de autoría y presenta la idea de "veleta de autoría". Destaca la complejidad de los factores involucrados en el establecimiento de la autoría científica, desde el punto de vista de la falta de consenso sobre los criterios que definen la autoría de una obra, así como en relación con las demandas y presiones pelo productivismo en las publicaciones. De esto se presenta dos esquemas de autoría.

Conclusiones: El reconocimiento de la autoría científica sigue siendo una condición que depende mucho más de los principios éticos que los autores disponen que las reglas y convenciones impuestas.

Palabras clave: Author. Escritura científica. Plágio. Ética.

Recebido em: 28.08.2012

Aceito em: 26.05.2015 